\title{
Performance of Bare and Sol-gel Coated DKDP Crystal Surfaces Exposed to Multiple 351-nm Laser Pulses in Vacuum and Air
}

P. Whitman, M Norton, M. Nostrand, W. Molander, A. Nelson, M. Engelard, D. Gaspar, D. Baer, W. Siekhaus, J. Auerbach, S. Demos, M. Staggs, and A. Burnham

This article was submitted to Boulder Symposium in Laser-Induced Damage in Optical Materials, Boulder, Colorado October 1-3, 2001

U.S. Department of Energy

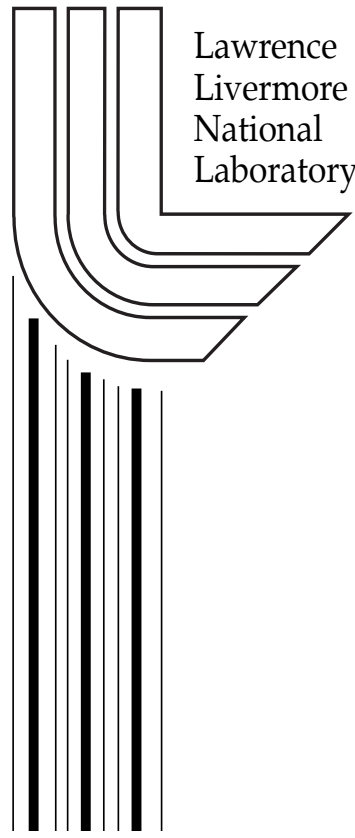

December 19, 2001 


\section{DISCLAIMER}

This document was prepared as an account of work sponsored by an agency of the United States Government. Neither the United States Government nor the University of California nor any of their employees, makes any warranty, express or implied, or assumes any legal liability or responsibility for the accuracy, completeness, or usefulness of any information, apparatus, product, or process disclosed, or represents that its use would not infringe privately owned rights. Reference herein to any specific commercial product, process, or service by trade name, trademark, manufacturer, or otherwise, does not necessarily constitute or imply its endorsement, recommendation, or favoring by the United States Government or the University of California. The views and opinions of authors expressed herein do not necessarily state or reflect those of the United States Government or the University of California, and shall not be used for advertising or product endorsement purposes.

This is a preprint of a paper intended for publication in a journal or proceedings. Since changes may be made before publication, this preprint is made available with the understanding that it will not be cited or reproduced without the permission of the author.

This report has been reproduced directly from the best available copy.

Available to DOE and DOE contractors from the Office of Scientific and Technical Information

P.O. Box 62, Oak Ridge, TN 37831

Prices available from (423) 576-8401 http:/ /apollo.osti.gov/bridge/

Available to the public from the National Technical Information Service

U.S. Department of Commerce 5285 Port Royal Rd., Springfield, VA 22161

http://www.ntis.gov/

\section{OR}

Lawrence Livermore National Laboratory

Technical Information Department's Digital Library

http://www.llnl.gov/tid/Library.html 


\title{
Performance of bare and sol-gel coated DKDP crystal surfaces exposed to multiple 351-nm laser pulses in vacuum and air
}

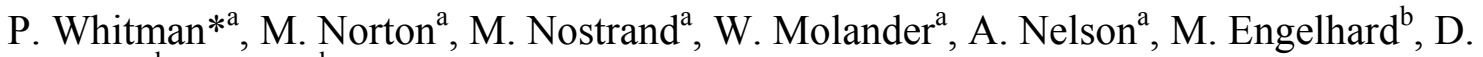 \\ Gaspar $^{\mathrm{b}}$, D. Baer ${ }^{\mathrm{b}}$, W. Siekhaus ${ }^{\mathrm{a}}$, J. Auerbach ${ }^{\mathrm{a}}$, S. Demos ${ }^{\mathrm{a}}$, M. Staggs ${ }^{\mathrm{a}}$, A. Burnham ${ }^{\mathrm{a}}$ \\ ${ }^{a}$ University of California, Lawrence Livermore National Laboratory, \\ 7000 East Avenue L-487, Livermore, California 94550, U.S.A. \\ UCRL-JC-144220 \\ ${ }^{\mathrm{b}}$ PNNL Environmental Molecular Sciences Laboratory, Richland, WA 99352
}

\begin{abstract}
We have investigated the surface degradation of bare and sol-gel coated deuterated potassium dihydrogen phosphate (DKDP) crystals when exposed to 351-nm laser pulses in atmospheric air and nitrogen and at pressures ranging from atmospheric down to $10^{-5}$ Torr vacuum. Optical microscopy, surface topography, surface chemical analyses, $351-\mathrm{nm}$ pumped photoemission maps, and photometry results have been used to characterize these samples. We report the occurrence of two potentially linked surface degradation phenomena: the development of increased photoemission and the development of unacceptable surface roughening in the region exposed to the beam in vacuum. We note no degradation for surfaces exposed in air or nitrogen at pressures exceeding 1 torr. Diamond-turned DKDP surfaces show a ubiquitous, lowintensity photoemission signature before exposure to any laser fluence. The observed reduction of this emission signal as a function of operating pressure and accumulated laser energy when crystals are exposed to 351-nm laser pulses in air can be correlated with the removal of surface carbon.
\end{abstract}

Keywords: KDP, potassium dihydrogen phosphate, photoemission, fluorescence, photoluminescence, vacuum, surface roughening, laser damage

\section{INTRODUCTION}

Earlier work at our laboratory ${ }^{1,2}$ reported the development of induced absorption and photoemission from the surfaces of fused silica and DKDP optics when exposed to 351-nm laser pulses in $10^{-5}$ Torr vacuum and the absence of induced absorption when these optics were tested in air at atmospheric pressure. Silica substrates which were subjected to hundreds of moderate fluence, nsec-scale pulses in $\sim 10^{-5}$ Torr vacuum developed a fluorescence signal attributed to formation of SiOx surface layer. Silica samples subjected to the same laser exposure in air did not noticeably degrade. This paper summarizes the results of a parallel set of experiments designed to explore the degradation behavior of bare and sol-gel coated deuterated potassium dihydrogen phosphate (DKDP) optics when exposed to $351-\mathrm{nm}$ laser pulses in air and $10^{-5}$ Torr vacuum. As previously reported ${ }^{2}$, bare DKDP surfaces subjected to many hundreds of laser pulses in vacuum developed an increased 'fluorescence' signal in the region exposed to the beam. Unlike fused silica, there was a significant (but lower) fluorescence signal for the unexposed areas of the DKDP and this signal was essentially eliminated in the regions exposed to 351-nm laser light in air. Furthermore, a severely damaged (roughened) region developed at the edge of the beam for the vacuum-exposed DKDP samples. This paper explores the role of surface chemistry on the background fluorescence in the unexposed regions and the development of increased photoemission and surface roughening in the presence of many pulses of high-fluence 351-nm light in vacuum. In addition, we report the positive effect of partial pressure in eliminating both surface roughening and photoemission.

* Correspondence: Email: whitman2@1lnl.gov; Telephone: 925424 3583; Fax: 9254225099 


\section{EXPERIMENT}

\subsection{Materials preparation and measurements}

Test samples were $5 \times 5 \times 1$-cm thick type II DKDP plates cut from a variety of commercial and experimental conventional and rapid growth boules as shown in Table 1. Sample deuteration level ranged from approximately $70 \%$ to $80 \%$. Linear absorption at $351-\mathrm{nm}$ (mainly due to iron contamination) ranged from $<0.2 \%$ to $3.5 \%$ per $\mathrm{cm}$. Surfaces of all crystals were single-point diamond finished and were cleaned by submersion in toluene baths employing ultrasonic agitation at both 40 and $70 \mathrm{KHz}$. Selected samples were subsequently cleaned using UV-ozone to remove residual organic contamination.

\begin{tabular}{|l|l|l|l|l|}
\hline Boule ID & Growth method & \multicolumn{2}{|l|}{$\begin{array}{l}\text { Absorption at 351-nm (per } \\
\text { cm) }\end{array}$} & $\begin{array}{l}\text { Impurities detected } \\
(>20-50 \mathrm{ppb})\end{array}$ \\
\hline & & Prism & Pyramid & \\
\hline $80 \%$ LL1 & Conventional & NA & $<0.3 \%$ & $\mathrm{~S}, \mathrm{As}, \mathrm{Rb}, \mathrm{Sr}, \mathrm{Ba}$ \\
\hline $80 \%$ LL6 & Conventional & NA & $<0.3 \%$ & $\mathrm{~S}, \mathrm{As}, \mathrm{Rb}, \mathrm{Sr}, \mathrm{Ba}$ \\
\hline $70 \%$ LL5 & Conventional & NA & $<0.3 \%$ & $\mathrm{Al}, \mathrm{As}, \mathrm{Rb}, \mathrm{Sr}, \mathrm{Ba}$ \\
\hline 727 & Rapid growth & $3.5 \%$ & $<0.3 \%$ & $\mathrm{Fe}, \mathrm{Al}$, \\
\hline AD-16 & Rapid growth & $<0.3 \%$ & $<0.3 \%$ & $\mathrm{Al}, \mathrm{Sb}, \mathrm{Ba}, \mathrm{Cr}, \mathrm{Sr}, \mathrm{Ba}$ \\
\hline BD-8 & Rapid growth & $0.3-1.3 \%$ & $<0.3 \%$ & $\mathrm{Al}, \mathrm{Fe}, \mathrm{Sr}, \mathrm{Ba}, \mathrm{Zn} ?$ \\
\hline
\end{tabular}

Table 1: Source and key characteristics of DKDP samples used in this study.

A 70-nm thick colloidal silica sol anti-reflection (AR) coating was applied to selected crystals. The coating was either the original laser-damage resistant coating described by Thomas ${ }^{3}$ and denoted as 'deammoniated sol' or a recently developed hydrophobic sol ${ }^{4}$ denoted as 'HMDS-treated sol'. Coatings were handdispensed using a small, commercial spin coater.

\subsection{Test facilities}

Unless otherwise noted, all laser exposures were conducted in the frequency-tripled Nd-glass SLAB-lab laser facility operated at $0.5 \mathrm{~Hz}$ repetition rate. The test beam was a 351-nm, 10-ns FWHM single-mode Gaussian temporal pulse shape. The spatial intensity profile (Figure 1) is roughly "flat-top" with nominally $2: 1$ modulation. The beam size was $7 \mathrm{~mm} \times 5.5 \mathrm{~mm}$ at the sample surface. Vacuum tests were conducted at nominally $10^{-5}$ Torr. Atmospheric pressure experiments were conducted in HEPA-filtered
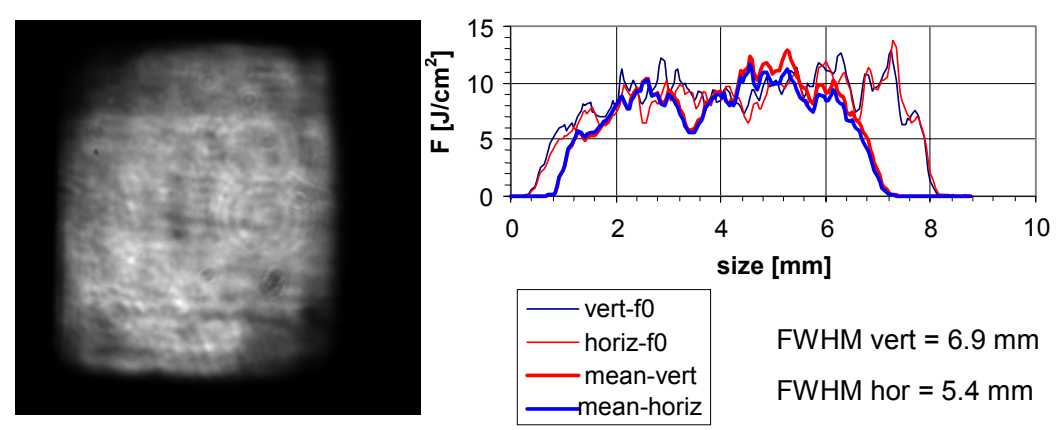

room air, nominally $50-60 \%$ relative humidity. Partial pressure experiments (1- 100 Torr) were conducted by flowing sufficient clean, dry air through an orifice to achieve the desired pressure in the vacuum chamber. Clean dry air was ensured by a series of point-of-use filters (molecular sieve, coconut charcoal getter, and HEPA).

Figure 1: Typical incident near-field beam image and horizontal and vertical lineouts of a typical beam fluence. (Diffraction patterns are from upstream damage in the laser chain.)

The setup, operation and diagnostics for this laser facility are detailed in earlier publications $^{5}$.

After laser irradiation was completed, samples were examined off-line using a variety of commercial and LLNL-built tools. Transmittance and surface reflection maps were generated at $351-\mathrm{nm}$ using a scanning laser photometer with polarization perpendicular to the extraordinary (sensitive) axis of the crystal. Photoemission and scatter images were obtained using a high resolution CCD-camera and 351-nm CW Arion probe beam as described by Demos et al ${ }^{6}$. Emission intensity and spectra over the visible (450-780 
$\mathrm{nm})$ and near infrared $(850-1000 \mathrm{~nm})$ were also quantified using tools described in previous articles ${ }^{1,7}$. Samples were imaged on a Leitz Aristocrat optical microscope in reflectance mode. Finally, representative samples were selected for characterization using atomic force microscopy (AFM) and Veeco NT2000 white light interferometer to characterize topography. Surface chemical analyses after photo-degradation was performed using a Physical Electronics Quantum 2000 scanning XPS system with a focused monochromatic $\mathrm{Al} \mathrm{Ka} \mathrm{x}$-ray $(1486.7 \mathrm{eV})$ source for excitation and a spherical section analyzer.

\section{RESULTS}

\subsection{Comparison of test results in vacuum vs. air}

All crystals (bare and coated) that were tested in 10-5 Torr vacuum (hereafter denoted as 'vacuum') showed readily visible surface roughening after 300 shots at either 6 or $10 \mathrm{~J} / \mathrm{cm}^{2}$. When the same bare crystals were subsequently tested in air, they developed no surface roughening. For bare crystals, the surface damage which formed during vacuum exposure was concentrated in a narrow $(\sim 1 \mathrm{~mm})$ band around the perimeter of the beam, leaving a 'footprint' of the beam which was readily visible with the unaided eye in room light. When these samples were illuminated with a low intensity $355-\mathrm{nm} \mathrm{CW}$ pump laser, areas exposed to the high fluence pulsed laser in vacuum and air could be readily distinguished by eye from the background signal generated by areas never exposed to laser light, as seen in Figure 2. Figure 2a shows increased photoemission throughout the area tested in vacuum, with especially increased

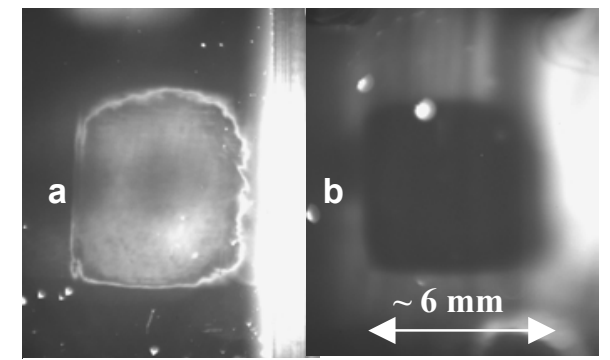

Figure 2: a) Surface fluorescence develops during vacuum exposure. b) Surface fluorescence is reduced when DKDP is exposed to multiple 351$\mathrm{nm}$ laser pulses in air. (Shown after 1000 shots at a) $8 \mathrm{~J} / \mathrm{cm}^{2}, 10 \mathrm{~ns}, 10^{-5}$ Torr and b) $6 \mathrm{~J} / \mathrm{cm}^{2}, 10 \mathrm{~ns}$, 760 Torr.) emission in a narrow ring at the edge of the test beam. Figure $2 \mathrm{~b}$ reveals a black 'footprint,' indicating reduced photoemission in the area tested in air. Figure 3 shows high magnification optical micrographs of typical damage such as that seen in Figure 2a. Areas inside the 'footprint' appeared undamaged in reflected light, while areas at the edge of the beam show evidence of catastrophic events. As is shown in Figure 4, the roughening pattern typically mirrors sharp gradients in the beam energy. Figures $5 \mathrm{a}$ and $\mathrm{b}$ show the photometry maps (transmission and reflection at 351-nm) for a bare crystal after the completion of testing in vacuum. An increase in reflection, indicating surface roughening, is not detectable after 30 shots, but changes in both reflection and transmittance are readily apparent after 300 shots at 6 or $10 \mathrm{~J} / \mathrm{cm}^{2}$.

For coated crystals, the damage associated with operation in vacuum was more difficult to detect with the unaided eye, but it was readily detected in photometry where disruption of the anti-reflection (AR) coating resulted in increased reflection loss. In contrast to bare crystals, damaged coated crystals generally exhibited transmittance loss (and reflection increase) throughout the entire area illuminated by the beam, as opposed to concentrating losses in the beam perimeter. The HMDS-coated crystals (Figure 6a) experienced much less 'damage' up to $0.3 \%$ increase in reflection compared to up to $3.6 \%$ increase in reflection for crystals coated with the standard 'deammoniated' sol (Figure 6b). There are two potential explanations for this result. It is likely that the weaker adhesion of the HMDS-treated sol allowed slow erosion of the sol vs. the more catastrophic 'flaking' of

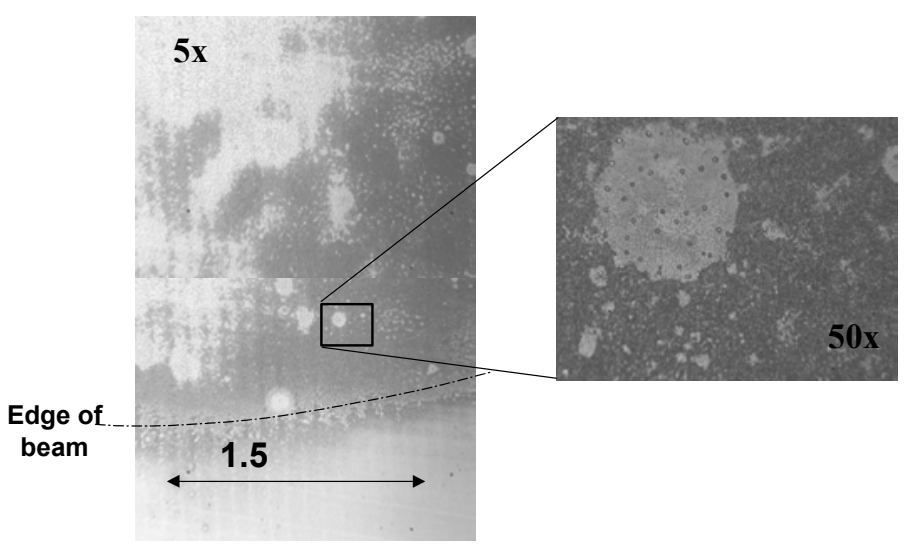

Figure 3: DKDP crystal surfaces roughen when exposed to many 351-nm laser pulses in vacuum. Pictured is the area near the edge of the beam for a type II diamond turned crystal after 1000 shots at $10 \mathrm{~J} / \mathrm{cm}^{2}, 10 \mathrm{~ns}, 10^{-5}$ Torr. 
the more strongly adhering/cohering standard sol. It is also possible that the accidental phthalate contamination of the standard sol (resulting in a shift of the UV- absorption edge of the sol from $<200 \mathrm{~nm}$ to $\sim 250 \mathrm{~nm}$ ) could have contributed to the poorer performance of the standard sol. In any case, the

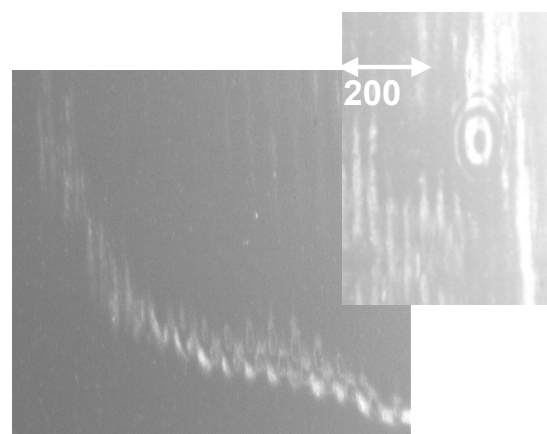

Figure 4: The roughening patterns mirror sharp gradients in the beam energy, as seen by the imprint of the 'bulls-eye' modulation in the high magnification image. The $\sim 65 \mu \mathrm{m}$ fringe spacing was observed for all 10 crystals tested over a period of more than 1 year.

Figure 8 shows high-resolution AFM images of the structure in the center and at the edge of the beam for a patch exposed to 1000 shots at $10 \mathrm{~J} / \mathrm{cm}^{2}$ in vacuum. At the outer edge of the beam (Figures $8 \mathrm{a}$ and $\mathrm{b}$ ), the structure evolves from round columns to a linear columnar structure that is aligned with the extraordinary axis of the crystal. As seen in Fig. 8c, the AFM detects little structure or roughness in the center of the beam footprint; this patch is quite similar to areas that never saw the laser. These results are consistent with the optical microscopy and white light interferometry.

The bare crystal shown in Figure 5 was probed with a 351-nm CW Ar pump beam to measure the intensity and spectrum of the emitted light. Figure 9 shows the integrated photoemission intensity $(400-780 \mathrm{~nm})$ as a function of shot fluence, environment, and number of shots for an uncoated crystal. Three trends are notable. First, the background photoemission signal from areas never exposed to the test laser was significantly greater than zero -- i.e., the "clean, bare" surfaces have significant photoemission. Second, the photoemission signal was greatly decreased, indeed almost extinguished, by as few as 30 shot at $6 \mathrm{~J} / \mathrm{cm}^{2}$ in air. (We did not investigate fewer shots or
HMDS-treated sol survived with surprisingly little damage considering the severe degradation experienced by the bare surfaces.

Micro-roughness of the laser-exposed areas on bare and coated crystals was compared to the unexposed surface roughness using white light interferometry. The damaged 'footprint' of the beam was readily apparent in white light interferometry as seen in Figure 7. There was no detectable roughening of the surface inside the vacuum-laser damage generated 'footprints' for bare crystals; other than the disruption which occurs at the edge of the beam, the diamond turning lines are unchanged inside and outside the laser test area. The coated samples are generally more sensitive to local beam modulation; Figure $7 \mathrm{~b}$ reveals an imprint of the test beam modulation in the coating. Typical microroughness measurements are indicated on the photometry map, Figures $5 \& 6$. (The air-exposed regions were not identifiable on the white light interferometer and hence not tested).
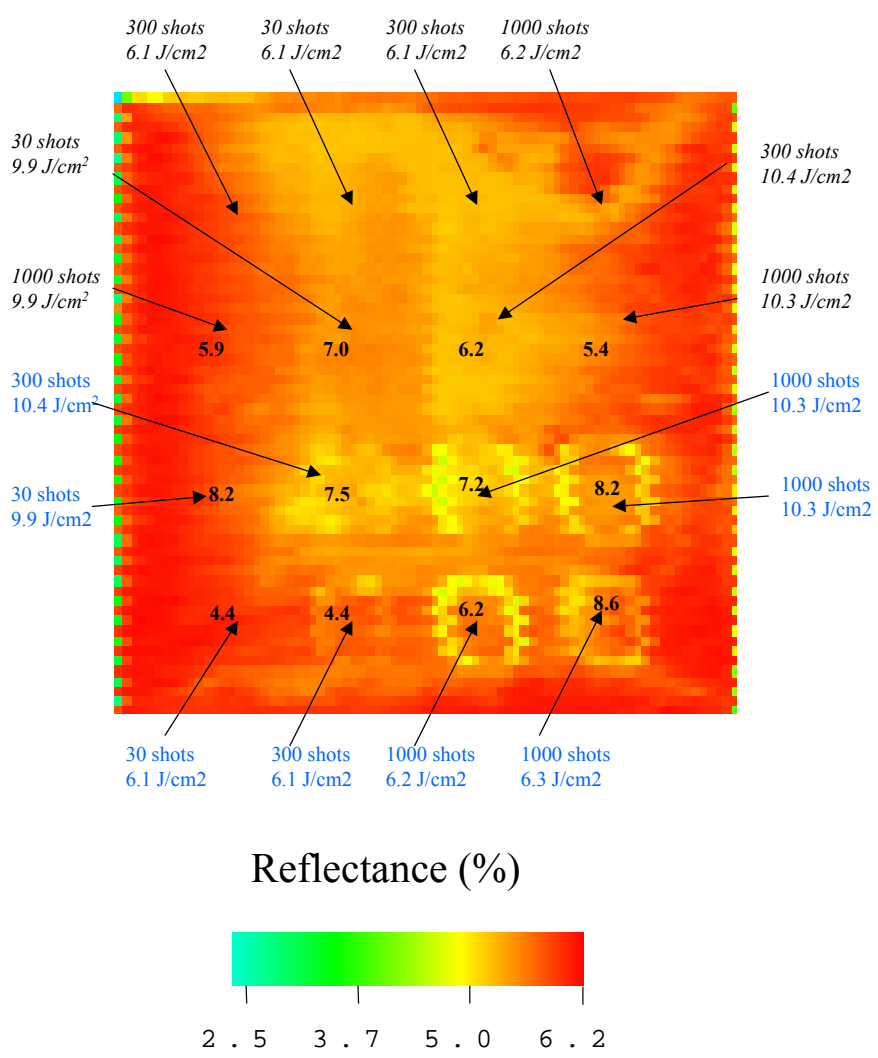

Figure 5: Reflectance map for an uncoated rapid growth DKDP crystal (5-cm square) exposed to multiple 351-nm, 10ns pulses in air and vacuum. Areas of laser damage (increased scatter) show up as rings of reduced specular reflection. Surface roughness (nm) as measured by white light interferometry after vacuum and before the air irradiation are indicated in center of irradiated areas. The test beam footprint is $\sim 7 \times 5.5 \mathrm{~mm}$. 
a)

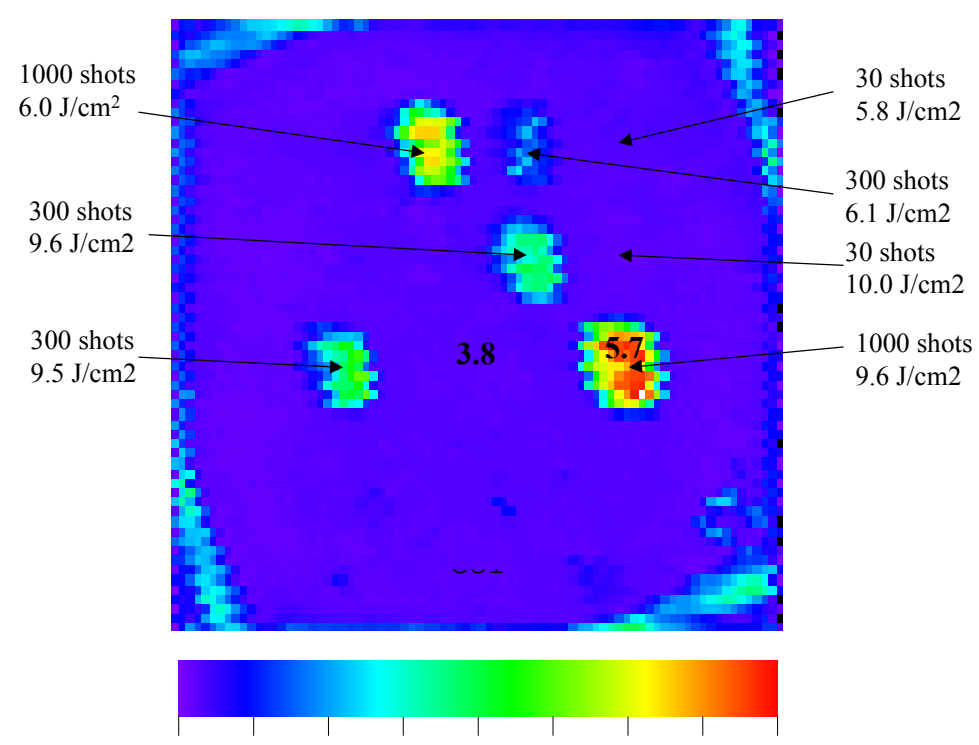

$\begin{array}{lllllllllllll}0.0 & 0.5 & 1.0 & 1.5 & 2.0 & 2.5 & 3.0 & 3.5 & 4.0\end{array}$

Reflectance (\%)

b)

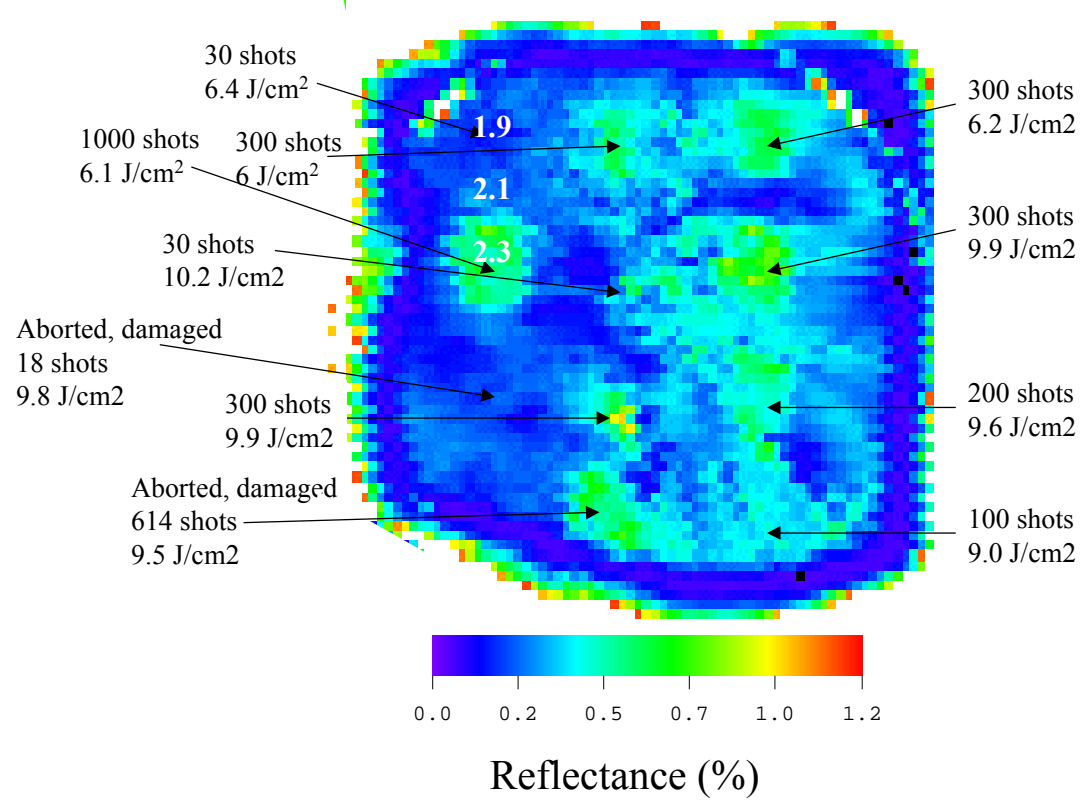

Figure 6: Reflection measured for a) standard de-ammoniated sol and b) HMDS-treated sol AR coated DKDP samples (5-cm square) after exposure to multiple 351-nm, $10 \mathrm{~ns}$ pulses in vacuum. Large-scale non-uniform reflectance pattern is due to thickness variations in the sol-gel coating. Localized rectangular patches of increased reflection are due to disruption of the AR coating by laser damage. Surface roughness (nm) as measured by white light interferometry after vacuum irradiation are indicated in center of typical irradiated and unirradiated areas; the nominal test beam size is $7 \times 5.5 \mathrm{~mm}$. 

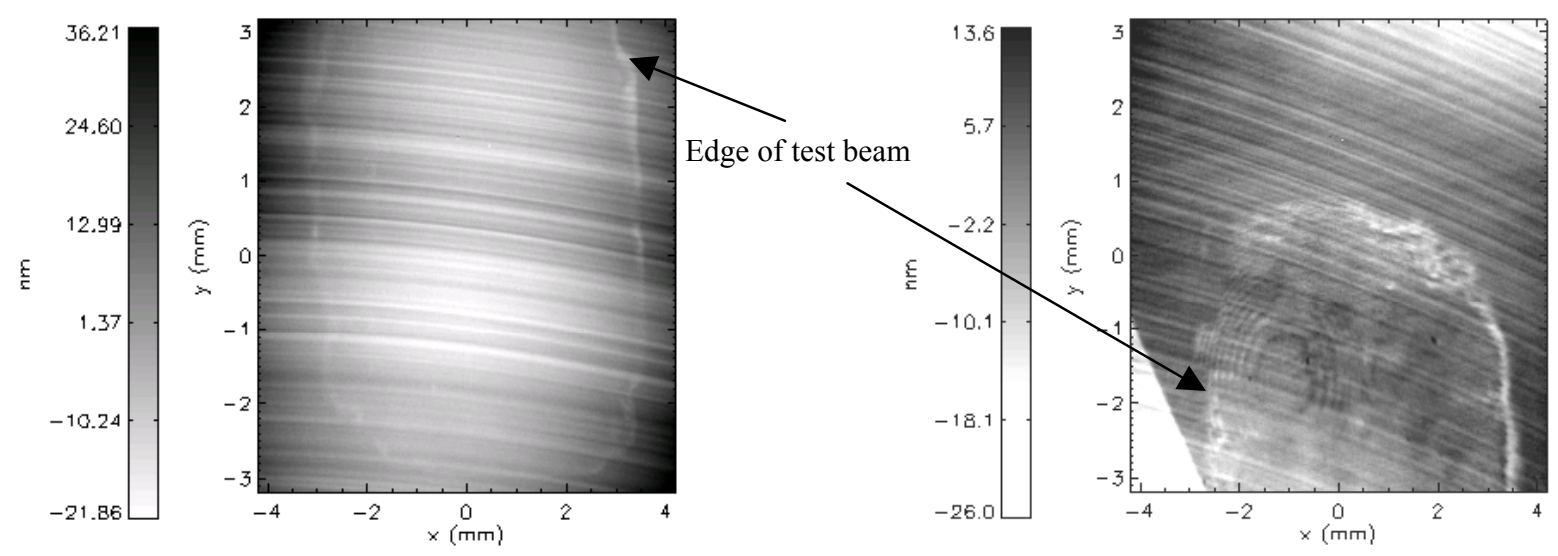

Figure 7: White light interferometry maps $(6 \times 8 \mathrm{~mm})$ detect roughening only at the edge of the test beam; diamond turning marks appear unperturbed except in areas of high beam modulation or at the edge of the beam. Left: bare surface after 1000 shots, $10 \mathrm{~J} / \mathrm{cm} 2$. Right: HMDS-treated sol-gel coated surface after 1000 shots 10 $\mathrm{J} / \mathrm{cm} 2$. Both samples irradiated in $10^{-5}$ Torr (vacuum).
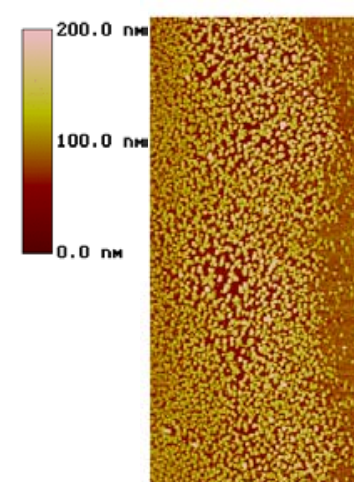
0 0 (a) edge of beam
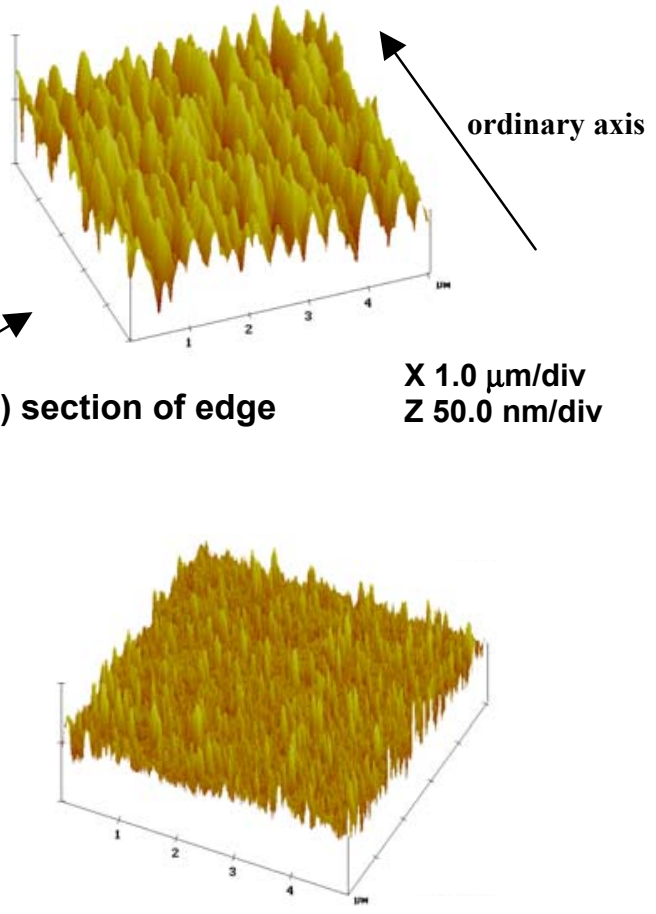

(c) center of beam
$X 1.0 \mu \mathrm{m} / \mathrm{div}$ $Z 20.0 \mathrm{~nm} / \mathrm{div}$

Figure 8: AFM images showing the amplitude of surface roughness on DKDP crystal after irradiation. The largest features occur at the edge of the test area and are aligned with the ordinary crystal axis. a) Plan view of $60 \times 60$ $\mu \mathrm{m}$ patch near the edge of the beam. b) High resolution 3-D view of $5 \times 5 \mu \mathrm{m}$ inscribed patch found shown in plan view. c) High resolution 3-D view of representative $5 \times 5 \mu \mathrm{m}$ patch in the center of the irradiated area. Irradiated 1000 shots, $10 \mathrm{~J} / \mathrm{cm}^{2}, 10 \mathrm{~ns}$ in vacuum $\left(10^{-5}\right.$ Torr $)$. 
lower fluence). This bleaching effect has also been observed for long exposures to the low intensity CW pump laser in air. Finally, the photoemission intensity was roughly doubled by 1000 shots at either 6 or $10 \mathrm{~J} / \mathrm{cm}^{2}$ in vacuum, as well as after a few dozen shots with the high intensity pulsed laser. This UV-vacuum-induced photoemission is stable for months; likewise, it has not been observed to bleach with either the low intensity $\mathrm{CW}$ probe laser or upon subsequent irradiation with two hundred $7.3 \mathrm{~J} / \mathrm{cm}^{2}$ $10 \mathrm{~ns}$ shots at $351 \mathrm{~nm}$.

The emission spectra for patches irradiated at 6 and $10 \mathrm{~J} / \mathrm{cm}^{2}$ in vacuum were similar to those previously reported for lower fluence irradiation and catastrophic surface damage on DKDP (2). The broad spectrum peaks at $\sim 500$ $\mathrm{nm}$ for all samples irradiated in vacuum. Unlike fused silica (2), there is no shift to longer wavelength emission with either increased fluence or increased number of shots. The 351-nm probe beam was also used to quantify the scatter intensity inside the central portion of each test area on the bare crystals. There was no assignable increase in scatter for the areas tested in air vs. vacuum. This is consistent with the white light interferometry (which found no roughening in the central portion of the beam) and microscopy results reported earlier.

\subsection{Effect of DKDP surface chemistry and partial pressures of air and nitrogen}

To test whether residual organic contamination is important, several crystals were UV-ozone cleaned using procedures previously demonstrated to eliminate even the last monolayer of hydrocarbon contamination . $^{8}$ Crystals were tested at $10^{-5}, 1,10$, and 100 Torr air as well as at 10 Torr nitrogen. While subtle sample-tosample differences persisted, there was no reduction in background photoemission for samples that were UV-ozone cleaned vs. those that had $0.1-0.3 \mu \mathrm{g} / \mathrm{cm}^{2}$ residual hydrocarbon. Furthermore, as seen in Figure 10, there was no reduction in roughening or induced absorption for samples irradiated in $10^{-5}$ Torr vacuum. Samples irradiated in 1 Torr air no longer developed surface roughening at the perimeter of the beam, but still showed evidence of some increased photoemission in the central portion of the beam. However, as seen in Figure 11, samples irradiated for 300 shots at $6 \mathrm{~J} / \mathrm{cm}^{2}$ in 5 Torr air are indistinguishable from those irradiated in air at 100 Torr or atmospheric pressure.

XPS surface chemical analyses confirmed that the observed photoemission behavior is not due to the nature of the residual carbon species. Figure 12 shows the relative intensity for the $\mathrm{C}-\mathrm{H}, \mathrm{C}-\mathrm{C}$, and $\mathrm{C}-\mathrm{O}$ species found on the surface of DKDP in areas which were unirradiated (background), and in areas which were irradiated in $10^{-5}$ Torr vacuum or in 10 Torr air. The relative ratio of the species found after irradiation in vacuum and at 10 Torr is quite similar, and both of these samples differ substantially from the spectrum found on the unirradiated surface. Further confirmation that carbon is not controlling the photoemission behavior can be found in Figure 13. The carbon concentration at the sample surface is not significantly different after 720 shots at $10 \mathrm{~J} / \mathrm{cm}^{2}$ whether the sample is irradiated at $10^{-5}$ Torr, 1 Torr, and 10 Torr. The higher carbon concentration found after only 320 shots at $6 \mathrm{~J} / \mathrm{cm}^{2}$ on the sample irradiated at $10^{-5}$ Torr does suggest that carbon cleanup may occur more rapidly at higher partial pressure. This is consistent with the partial cleanup of background emission seen in the Figure $10 \mathrm{~b}$ footprints generated at 1 Torr. 
A final set of experiments was executed to test whether oxygen is required to eliminate induced photoemission and/or surface roughening. Figure 14 shows reflectance maps for bare and HMDS-treated sol coated DKDP samples tested under a variety of conditions, including 10 Torr dry nitrogen, 1,5 , and 10 Torr dry air, and $10^{-5}$ Torr vacuum. These reflectance maps confirm the earlier observation that 1 Torr air is sufficient to eliminate the surface roughening on DKDP. Furthermore, this data suggest that nitrogen is as effective as air at eliminating surface roughening. Figure 15 shows the photoemission maps of the bare and coated optic after 1000 shots in 10 Torr air or nitrogen. The appearance of the image of the laser modulation (bulls-eye) in the coated sample irradiated in nitrogen but not the sample irradiated in air suggests that air may be slightly more effective at preventing degradation than nitrogen. However, this difference is slight and has not been replicated.

\section{Without UV-ozone cleaning}
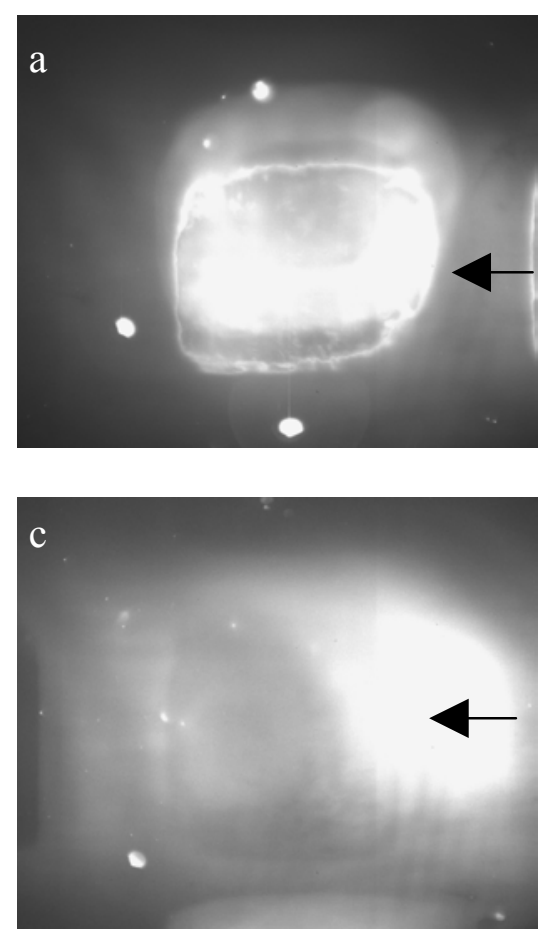

\section{With UV-ozone cleaning}
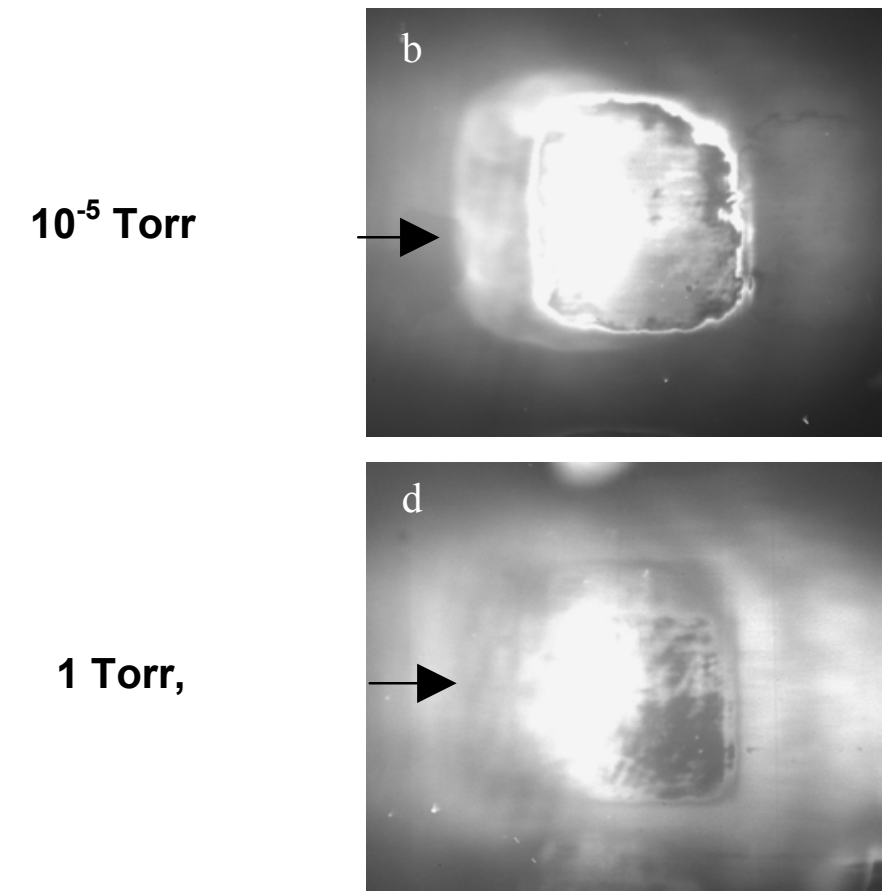

Figure 10: UV-Ozone cleaning had no observable effect on either photoemission or roughening behavior. Photoemission maps a) without and b) with UV-ozone cleaning, irradiated at $10^{-5}$ Torr. Photoemission maps c) without and d) with UV-ozone cleaning, irradiated at 1 Torr. All photographs obtained after 300 shots, $6 \mathrm{~J} / \mathrm{cm}^{2}, 10 \mathrm{~ns}, 351-\mathrm{nm}$.
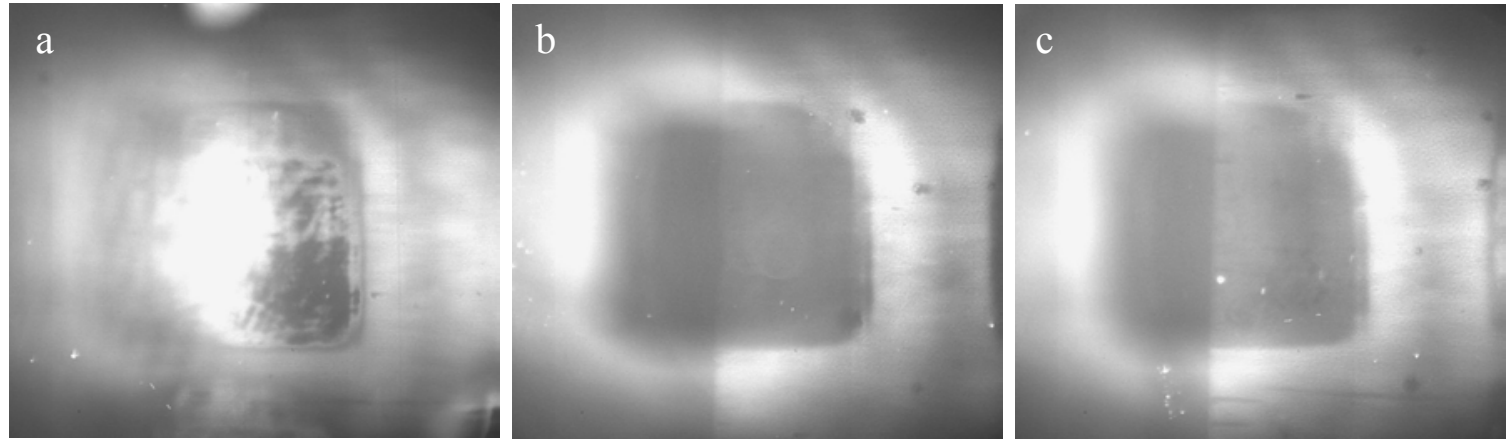

Figure 11: The reduction of background fluorescence occurs readily with UV exposure at pressures above 5 Torr air. Shown above are fluorescence images of the surface of UV-ozone cleaned DKDP taken after 300 shots at 6 $\mathrm{J} / \mathrm{cm}^{2}$ in a) 1 Torr, b) 5 Torr, and c) 100 Torr air. Figure 11a still shows some fluorescence structure inside the area irradiated by the laser. 


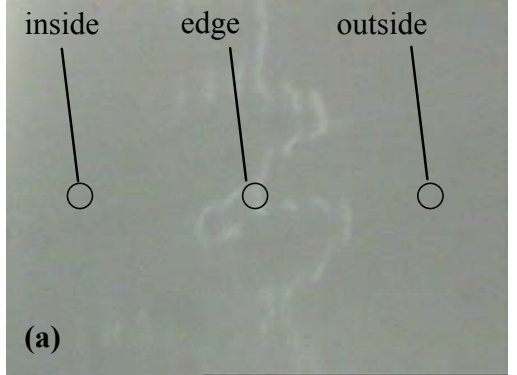

Vacuum Site 2 $6.4 \mathrm{~J} / \mathrm{cm}^{2}$ for 323 shots

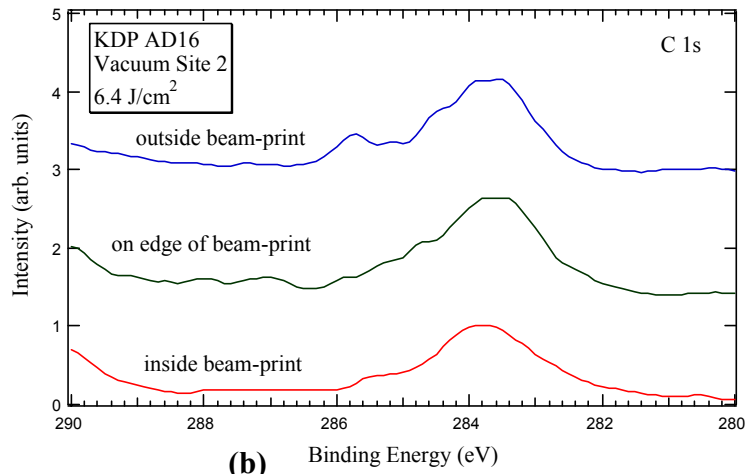

(b) Binding Energy (eV)
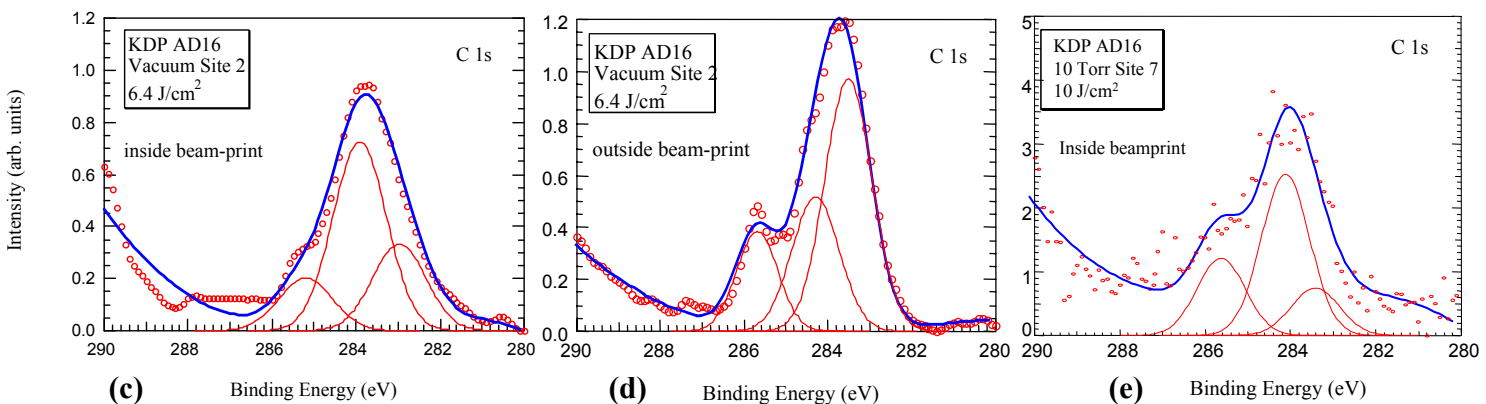

Figure 12: XPS surface chemical analyses for a sample that was not UV-ozone cleaned indicate that fluorescence behavior is not due to carbon. Figure (b) compares the binding energy of carbon found just inside, at the edge and just outside the edge of the beam footprint shown in Figure a. The C1s XPS profiles shown in (b) can be deconvoluted into three primary binding energies associated with $\mathrm{C}-\mathrm{C}$ at $283 \mathrm{eV}, \mathrm{C}-\mathrm{H}$ at $284 \mathrm{eV}$, and C-O at 285$6 \mathrm{eV}$; an unirradiated patch (d) is compared to patches irradiated in vacuum (c) and at 10 Torr (e).

\section{DISCUSSION}

Marshall ${ }^{10}$ reports the occurrence of induced absorption at $266 \mathrm{~nm}$ that has both transient and long-lived components in both KDP and DKDP. The absorption was suggested to arise from an induced defect state resulting from the promotion of an electron into the conduction band by two-photon absorption and subsequent relaxation to a long-lived trapped defect site, which could then be optically or thermally bleached. Our results only probe long-lived defects, since the characterization is hours to days later. Also, our induced absorbance is thought to occur only on the surface, so its relationship to Marshall's work is unclear.

Two hypotheses were suggested to explain the difference in performance for DKDP irradiated at atmospheric pressure vs. DKDP irradiated in $10^{-5}$ Torr vacuum. One hypothesis was that oxygen is required either to provide non-detrimental cleanup of hydrocarbons from the DKDP surface or to repair UV-induced defects. The other hypothesis was that atmospheric pressure provided better heat transfer and hence reduced the thermal insult to the surface.

Hydrocarbon contamination has been previously implicated in surface degradation ${ }^{11,12}$. Formation of an enhanced degradation at the beam edge has been attributed to deposition

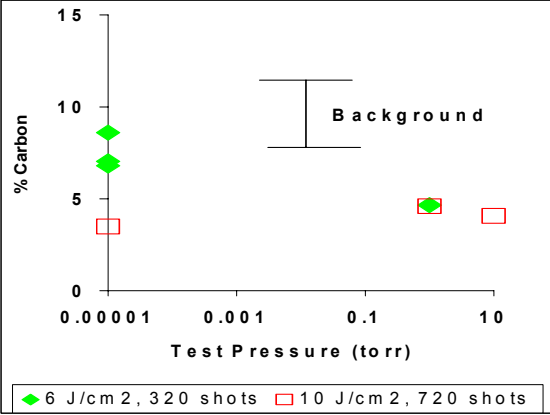

Figure 13: Comparison of the surface carbon concentration after multiple $351-\mathrm{nm}$ laser shots in vacuum, 1 , and 10 Torr air with the background surface carbon concentration for the sample shown in Figure 12.

of carbon to that location ${ }^{11}$. Residual diamond-turning shower oil could conceivably be the source of the background fluorescence found to some degree on all diamond-turned DKDP samples, and furthermore, 

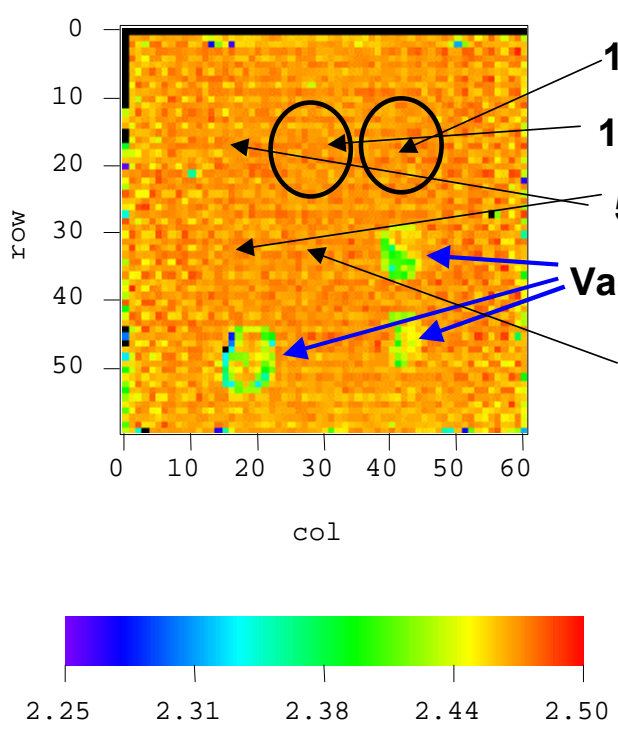

(a) Percent Reflectance
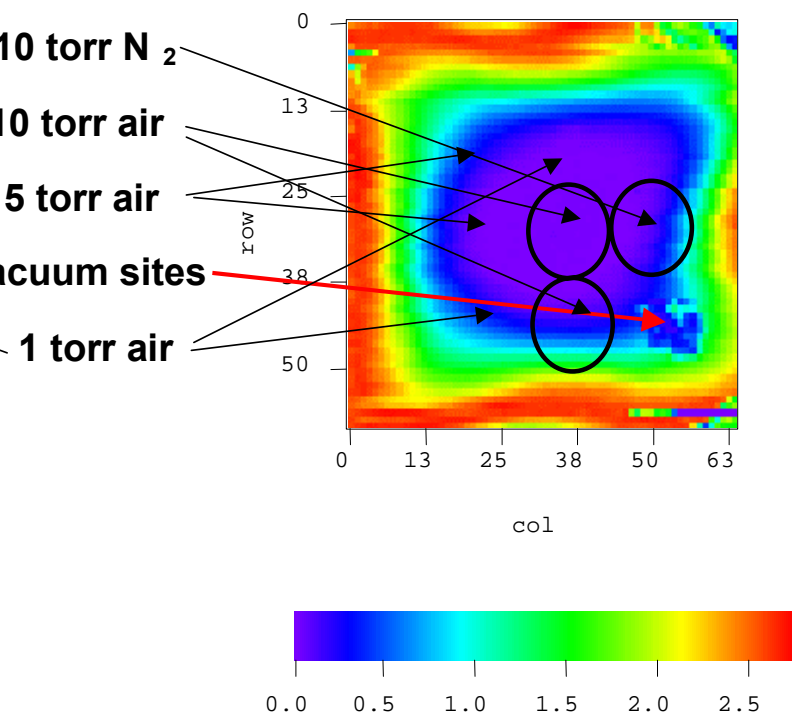

(b) Percent Reflectance

Figure 14: Reflectance maps for 5-cm square a) bare and b) AR coated, UV-ozone cleaned DKDP crystals after irradiation in at a variety of pressures from vacuum $\left(10^{-5}\right.$ Torr $)$ to 10 Torr and in both air and nitrogen. Both bare and coated surfaces roughen in vacuum, as indicated by the decrease in the bare surface and the increase in coated surface reflection.

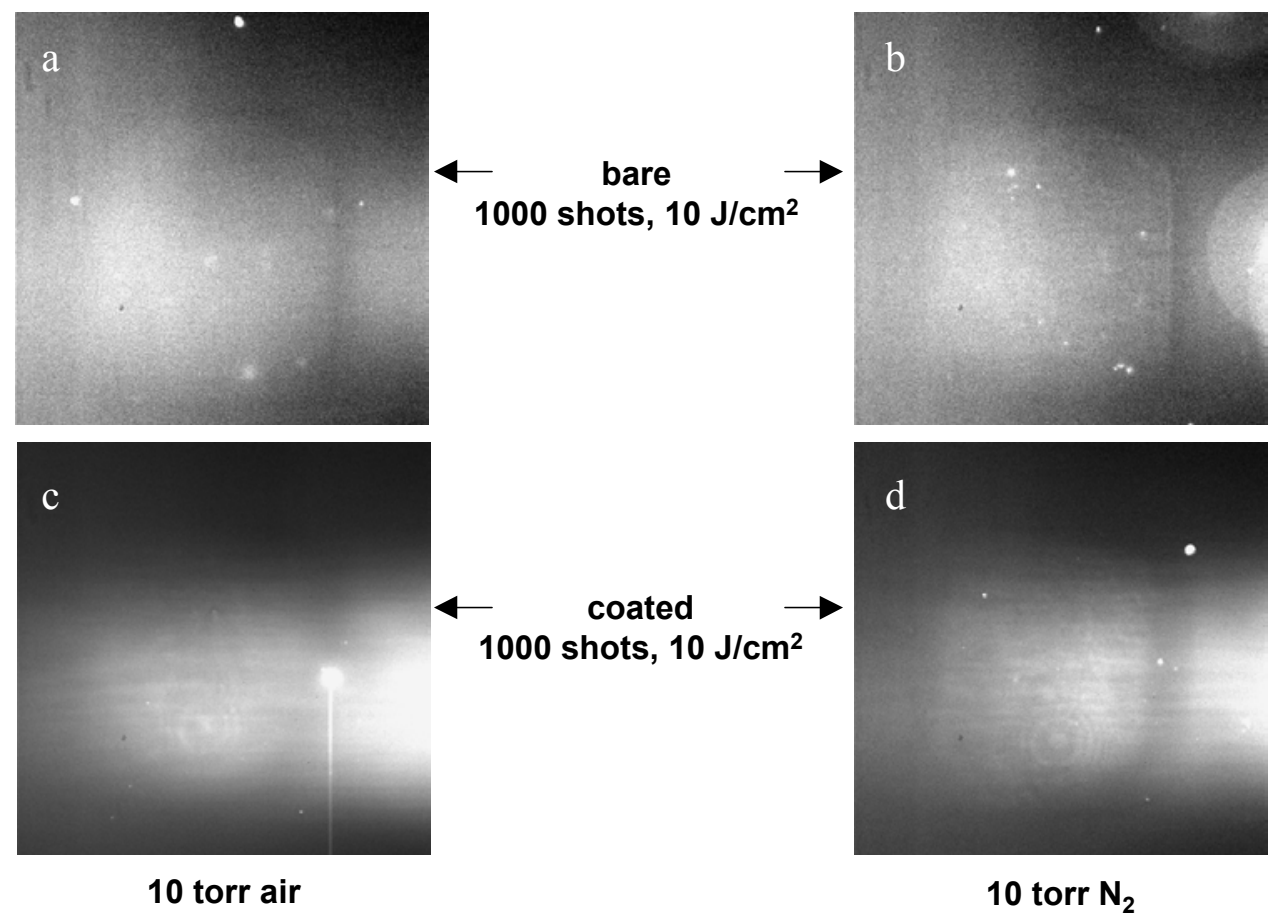

Figure 15: Fluorescence maps suggest that nitrogen may be less effective than air at preventing degradation. Figures a) bare and c) coated, irradiated in 10 Torr air. Figures b) bare and d) coated, irradiated in 10 Torr nitrogen. All patches irradiated 1000 shots at $10 \mathrm{~J} / \mathrm{cm}^{2}, 10 \mathrm{~ns}, 351-\mathrm{nm}$. 
this residual carbon could play a role in the development of damage (roughening) and increased photoemission on DKDP samples irradiated in vacuum. Hydrocarbons might harmlessly decompose to volatile carbon monoxide and dioxide in the presence of air, but might char to highly absorbing carbon species in the absence of oxygen. However, the data presented above suggest that hydrocarbon cleanup is not responsible for the reduction in background photoemission or the improved laser-damage performance at $>1$ Torr. Mitigation of similar surface degradation of fused silica and dichroic mirrors has had mixed results: some find that inert gases can inhibit surface degradation ${ }^{13}$, and others find improvement only with oxygen $^{12,14}$.

Furthermore, tests conducted in 10 Torr nitrogen suggest that oxygen is not required, or at least has only a minor effect. Simple calculations indicate that the contribution of natural convection is negligible compared to conduction through the sample for any plausible value of surface absorption and hence improved heat transfer is an unlikely explanation for the observed effect. (To ensure that we were not looking at a thermally activated process that was induced by the $0.5 \mathrm{~Hz}$ repetition rate, one sample was tested at $0.05 \mathrm{~Hz}$; roughening behavior was unchanged.) Yet, the almost comparable performance of dry nitrogen and dry air at 10 Torr suggests that pressure may be the most important variable. Perhaps the role of pressure is to prevent or facilitate bleaching of UV-induced surface defects, hence preventing run-away surface absorption and concomitant damagingly high prompt temperature rises. Earlier work has also found that "inert" gases are nearly as effective as oxygen at preventing surface degradation, but no mechanism has been demonstrated ${ }^{13}$.

The presence or absence of physisorbed or chemisorbed water on the surface of the DKDP could also play a role either through evaporative cooling or chemical reaction. Hirsch and Adams ${ }^{9}$ report the chemical sensitization of KDP surfaces irradiated with $1.5 \mathrm{keV}$ Ar ions, $1000 \mathrm{eV}$ electrons, or $\mathrm{Cu}-\mathrm{K} \alpha$ photons for 1.5 -3 hours in high vacuum $\left(\sim 5 \times 10^{-5}\right.$ Torr $)$. They report hydrogen gas evolution and surface corrosion that occurs only after subsequent exposure to atmospheric water vapor. This sensitization is attributed to generation of metallic $\mathrm{K}$, which can then react with water vapor to begin the corrosion reactions with evolution of hydrogen gas. The morphology of the corrosion pits generated with Ar ion bombardment is described as rods that are preferentially aligned with the crystallographic axes. Furthermore, they find that the rods formed are lower density and substantially larger and more elongated as they move into the weakly irradiated areas at the edge of the target region. They attribute the observed size distribution to the density of activated sites. Hirsch and Adams observations are reminiscent of the inchoate morphology found at the edge of the area irradiated with $3.6 \mathrm{eV}(351-\mathrm{nm})$ photons in our experiments (see Figure 8). However, there are also substantial differences between the surface roughening which we have observed and that of Hirsch. Most importantly, surface roughening is clearly detected during vacuum irradiation (does not require subsequent exposure to atmospheric humidity) and is suppressed by atmospheres where chemisorbed and free water vapor is likely to be more abundant.

It is also conceivable that impurities play a role in the roughening or fluorescence, but through a mechanism that occurs only at the surface in vacuum. Marshall has reported that impurities, particularly As, play a role for radiation-induced absorption in KDP and DKDP, ${ }^{15}$ and Runkel et al ${ }^{16}$ report a similar result for induced absorption for exposure to 308 and 248-nm light. However, there is no readily apparent difference in either the induced roughness or fluorescence in the samples we explored, which represent a considerable difference in impurity levels, particularly across the pyramid-prism boundary.

\section{CONCLUSIONS}

As-manufactured diamond-turned DKDP surfaces exhibit photoemission that can be bleached by exposure to 351-nm light in air. This bleaching occurs more rapidly (fewer shots) at pressures above 1 Torr. UVozone cleaning prior to laser exposure does not noticeably reduce this background emission, indicating that the emission source is probably a KDP-defect structure and not organic contamination.

Roughening of DKDP surfaces only occurs at operating pressures below 1 Torr. Nitrogen, dry air and humid air can all prevent roughening, suggesting that oxygen is not required to suppress roughening. Roughening does not appear to be caused by organic surface contamination - surface carbon is removed equally well in vacuum and air. Induced absorption, inferred from the increased photoemission, occurs when DKDP surfaces roughen by exposure to accumulated 351-nm laser light at greater than $6 \mathrm{~J} / \mathrm{cm}^{2}$ in 
vacuum. Unlike the induced absorption observed in fused silica, this induced absorption in DKDP is not bleached by subsequent exposure to 351-nm light in air. We currently have no satisfactory explanation for the mechanism of this phenomenon.

\section{ACKNOWLEDGEMENTS}

The authors wish to acknowledge the contributions of the many LLNL associates who contributed to this effort: Gene Donohue, Kurt Neeb, Dave Roberts, and Doug Shier for setting up and conducting the SLAB lab experiments; Eric Miller, Ken Foster, Robert Cheek, Will House, and Tim Sarginson for metrology and sample preparation; and Paul Wegner and Mike Fluss who provided technical advice.

This work was performed under the auspices of the U. S. Department of Energy by University of California, Lawrence Livermore National Laboratory under Contract No. W-7405-ENG-48

\section{REFERENCES}

1. A. K. Burnham, M. Runkel, S. G. Demos, M. R. Kozlowski, and P. J. Wegner, "Effect of vacuum on the occurrence of UV-induced surface photoluminescence, transmission loss, and catastrophic surface damage," Photonics for Space Environments VII, SPIE Proc. 4134, pp. 243 - 253, 2000.

2. S. G. Demos, A. Burnham, P. Wegner, M. Norton, L. Zeller, M. Runkel, M. R. Kozlowski, M. Staggs, and H.B. Radousky, "Surface defect generation in optical materials under high fluence laser irradiation in vacuum," Elec. Lett. 36(6), pp. 566 - 567, 2000.

3. I. M. Thomas, "High laser damage threshold porous silica antireflective coating," Appl. Opt. 25(9), $1481-1483,1986$.

4. E. K. Wheeler, J.T. McWhirter, P.K. Whitman, C.Thorsness, J. De Yoreo, I.M. Thomas, "Scatter loss from environmental degradation of KDP crystals," Laser-Induced Damage in Optical Material:1999 SPIE Proc. 3902, pp. 451-459, 2000.

5. M. A. Norton, Z. Wu, L. W. Hrubesh, Z-L. Wu, E. Donohue, M.D. Feit, M.R. Kozlowski, D. Milam, K.P. Neeb, W. A. Molander, A.M. Rubenchick, W.D. Sell, and P.Wegner, "Growth of laser-initiated damage in fused silica at 351-nm," Laser-Induced Damage in Optical Material:2000 SPIE Proc. 4347, p.468, 2001.

6. S. G. Demos, M. R. Kozlowski, M. Staggs, L. L. Chase, A. Burnham, H. B. Radousky, "Mechanisms to explain damage growth in optical materials", Laser-Induced Damage in Optical Material:2000 SPIE Proc. SPIE Proc. 4347, 277, 2001.

7. S. G. Demos, M. Staggs, M. Yan, H. B. Radousky and J. J. De Yoreo, "Microscopic fluorescence imaging of bulk defect clusters in $\mathrm{KH}_{2} \mathrm{PO}_{4}$ crystals", Optics Lett. 24, 268, 1999.

8. A. J. Nelson, T. van Buuren, E. Miller, T. A. Land, C. Bostedt, N. Franco, P. K. Whitman, P. A. Baisden and L. J. Terminello and T.A. Callcott, X-ray absorption analysis of KDP optics", J. Electron Spectrosc. Related Phenomena 114, 873-878, 2001.

9. E. H. Hirsch and T. R. Adams, "Ion bombardment of materials containing alkali metals or alkaline earths," J. Phys. D: Appl. Phys. 23, pp. 1621 - 1632, 1979.

10. C. D. Marshall, S. A. Payne, M. A. Henesian, J. A. Speth, and H. T. Powell, "Ultraviolet Induced Transient Absorption in Potassium Dihydrogen Phosphate and its Influence on Frequency Conversion," J. Opt. Soc. Am. B 11, 774-785 (1994).

11. L. Bruel, P. Delmas, "The use of high-power dye laser beams during long periods induce chemical vapor deposition," Laser-Induced Damage in Optical Materials 2000, SPIE vol. 4347, 285-293 (2001). 
12. E. Hovis, B. A. Shepherd, C. T. Radcliffe, A. L. Bailey, and W. T. Boswell, "Optical damage at the part per million level: the role of trace contamination in laser induced optical damage," SPIE vol. 2114, pp. 145-153, 1993.

13. M. Stephen, B. Van Zyl, R. C. Amme, "Degradation of vacuum-exposed $\mathrm{SiO}_{2}$ laser windows," SPIE Vol. 1848, pp. 106-110 (1992).

14. Chow, L. V. Berzins, P. A. Arnold, G. V. Erbert, "Reversible laser damage of dichroic coatings in a high average power laser vacuum resonator," SPIE Vol. 3902, pp. 283-291 (2000).

15. D. Marshall, J. A. Speth, L. D. DeLoach, and S. A. Payne, "Penetrating radiation impact on NIF final optic components," Proceedings of $2^{\text {nd }}$ Annual Conference on Solid State Lasers for Application to Inertial Confinement Fusion, SPIE Vol. 3047, pp. 343-363 (1997).

16. Runkel, K. Neeb, M. Staggs, J. Auerbach, A. Burnham, "The results of raster-scan laser conditioning studies on DKDP triplers using Nd:YAG and excimer lasers," This proceedings. 